\title{
TRANSCULTURACIÓN NARRATIVA: UTOPÍA PROGRAMÁTICA MODERNIZANTE
}

\author{
NARRATIVE TRANSCULTURATION: \\ MODERNIZING PROGRAMMATIC UTOPIA
}

\author{
Hugo Herrera Pardo \\ Universidad Andrés Bello. Santiago, Chile \\ hugo.herrera.pardo@gmail.com
}

\begin{abstract}
Resumen: Este artículo construye la travesía histórica del concepto transculturación narrativa propuesto por Ángel Rama. El análisis se basa, metodológicamente, en el examen de la discrepancia que se produce entre la proposición teórica y su recepción. A lo largo del análisis, además, las reflexiones surgidas en torno a transculturación narrativa se contrastan a otras metáforas culturales latinoamericanas contemporáneas a la formulación ramiana, tales como Calibán (Fernández Retamar), Malandraje (Candido), Fuera de lugar (Schwarz), Nacionalismo diferencial (De Campos), Filtragem (Bosi) y Literaturas heterogéneas (Cornejo Polar).
\end{abstract}

Palabras clave: Ángel Rama, metáforas culturales, pensamiento crítico y literario latinoamericano.

\begin{abstract}
This article builds the historic crossing of the narrative transculturation concept proposed by Angel Rama. The analysis is based, methodologically, in the examination of the discrepancy that occurs between the theoretical proposition and its reception. Throughout the analysis also reflections emerged around narrative transculturation contrast to other cultural metaphors contemporary to the formulation of the uruguayan literary critic, such as Calibán (Fernández Retamar), Malandraje (Candido), Fuera de lugar (Schwarz), Nacionalismo diferencial (De Campos), Filtragem (Bosi) y Literaturas heterogéneas (Cornejo Polar).
\end{abstract}

Keywords: Ángel Rama, cultural metaphors, Latin American critic and literary thought.

Recibido: 20.08.2015. Aceptado: 18.12.2015. 


\section{Exclusión y límite}

$\mathrm{P}$ ENSADA Y FORMADA en aquella intermedia zona de contacto en que colisionan elementos de procedencia externa y componentes de la estructura cultural tradicional latinoamericana, la versión propuesta por Ángel Rama de la "transculturación" ensayada primeramente por Fernando Ortiz (1987 [1940]) intentaba superar la imagen sincrética de transformación cultural del continente, entendida como conjunto de aportes entre comunidades puestas en relación. Zona intermedia de contacto donde se asumía que llegaban a confluir "universalidad" e "identidad nacional” y sobre la cual precedentemente venían trabajando tanto la Teoría de la dependencia ${ }^{1}$ como la antropología latinoamericana, pero que históricamente representó un espacio de reflexión privilegiado dentro del pensamiento crítico y literario latinoamericano, constituyendo el lugar impositivo pensado para situar su simbólica frontera de exclusión ${ }^{2}$. La centralidad de este espacio es de tan larga data que incluso -y haciendo abstracción de la singularidad de sus diversas elaboraciones históricas- puede retrotraerse con nitidez, al menos, hasta el Facundo. Dentro de la incidencia de la antropología cultural sobre la crítica literaria latinoamericana, transculturación narrativa

${ }^{1}$ A este respecto, cabe señalar que las diversas formaciones de la narrativa regionalista latinoamericana que Rama analiza como respuesta cultural a formaciones urbanas y extranjerizantes, ya habían tenido un precedente crítico formalizado en el artículo de Antonio Candido "Literatura y subdesarrollo" (1991 [1970]).

${ }^{2}$ Tomo este concepto de Laclau $(1987,1995)$ para comprender la construcción diferencial del significado, en la cual lo externo se piensa como amenaza, presente en gran parte de las representaciones culturales de América Latina y que, como se sabe, constituye una de las operaciones eurocéntricas más características. Según Laclau, los límites auténticos de todo sistema significativo en ningún modo son neutrales, sino que en cada caso constituyen una exclusión. Surge así una subversión del sistema significativo, dado que lo que permanece del otro lado del límite de exclusión se presenta como la imposibilidad del lado de acá de dicho límite. En otras palabras, en un sistema significativo los límites son siempre antagónicos. A esa figura del límite excluyente, Laclau lo denomina frontera de exclusión, la cual conlleva a una serie de reflexiones. Entre ellas, por ejemplo, Laclau postula que aquella frontera abre el juego para dos lógicas complementarias: las lógicas de diferencia y equivalencia. Por una parte, todo elemento del sistema mantiene un rasgo diferencial en la medida en que es diferente de los otros. Por otro lado, al pertenecer una serie de elementos al lado interno de la frontera de exclusión, se vuelven de algún modo equivalentes entre sí. Por consiguiente, la identidad de cada elemento al interior del sistema se encuentra constitutivamente dividida: en tanto diferencia al distinguirse de los otros elementos y como equivalencia al entrar en una relación de tal tipo con otros elementos que pertenecen al mismo lado del sistema. 
constituye su producción más elaborada. Aunque en ella también puede apreciarse cierto grado de incidencia de la reflexión cultural de la escuela de Frankfurt y resabios del estructuralismo. Este último sobre todo a nivel de análisis textual.

La hipótesis que Rama desarrolla en una serie de formidables interpretaciones de textos sobre los "transculturadores narrativos" (Arguedas, Rulfo, Guimaraes Rosa, García Márquez, Roa Bastos) se concentra en presentar el modo de cómo ciertos elementos de la cultura tradicional latinoamericana, investidos de una gran fuerza significativa, como el caso del "laconismo sintáctico" tan presente en los transculturadores pero también en autores como César Vallejo o Graciliano Ramos, resistían a los embates de la modernización impuestos por fuentes externas. Proceso, a su vez, definido en base a la interacción de cuatro operaciones esenciales (pérdidas, selecciones, redescubrimientos e incorporaciones), las cuales, en la visión de Rama, acababan por rearticular globalmente la cultura tradicional, produciéndose para ello la intensificación de alguno de sus elementos. Tal como asevera Rama en su análisis, esta "plasticidad cultural", "capacidad selectiva" o "tarea selectiva sobre la tradición" se fundamenta sobre dos comprobaciones. Por una parte, el registro de que "la cultura presente de la comunidad latinoamericana (que es un producto largamente transculturado y en permanente evolución) está compuesta de valores idiosincráticos, los que pueden reconocerse actuando desde fechas remotas" (2007, p. 40). $\mathrm{Y}$ en segundo lugar, también actúa como fundamento la corroboración de

[L]a energía creadora que la mueve, haciéndola muy distinta de un simple agregado de normas, comportamientos, creencias y objetos culturales pues se trata de una fuerza que actúa con desenvoltura tanto sobre su herencia particular, según las situaciones propias de su desarrollo, como sobre las aportaciones provenientes de fuera. Es justamente esta capacidad para elaborar con originalidad, aun en difíciles circunstancias históricas, la que demuestra que pertenece a una sociedad viva y creadora, rasgos que pueden manifestarse en cualquier punto del territorio que ocupa aunque preferentemente se los encuentre nítidos en las capas recónditas de las regiones internas (2007, pp. 40-41).

Son notorias las bases antropológicas de esta energía creadora que refiere Rama. Entendida como capacidad dinámica de una sociedad viva sobre la cual descansa, esta energía creadora es la base, también, de uno 
de los principales aportes de la propuesta ramiana: su valor metodológi$\mathrm{co}^{3}$. Aspecto al que por lo demás se debe en buena parte su preservación dentro del discurso crítico latinoamericano en las décadas posteriores a su circulación, porque como enuncia Mabel Moraña, si la noción de alguna u otra forma ha logrado persistir, esto responde "en gran medida gracias al incesante proceso de recontextualización y resemantización que la articula a áreas, periodos, disciplinas y proyectos ideológicos diversos" (1997, p. 137) ${ }^{4}$. No obstante, es a partir de estos mismos aportes antropológicos que la categoría reafinada por Rama encuentra algunos de sus principales obstáculos.

Para explicarlo, atendamos a la discrepancia que se produce entre la proposición teórica-metodológica y su recepción. Dicho caso podría sintetizarse en la pregunta ¿̇si uno de los mayores fuertes de la propuesta de Rama radicaba en su valor metodológico, por qué entonces su recepción crítica atendió de modo fundamental a la interrogante por la posición de los intelectuales en un panorama transnacionalizado? A esta discrepancia subyacen fuerzas externas que se encontraban fuertemente presionando la frontera de exclusión del pensamiento crítico y literario latinoamericano de la época, causando una crisis irreconciliable entre problemáticas emergentes y algunos de los elementos residuales que también se manifestaban en otras metáforas culturales del periodo, como Calibán y Fuera de lugar. Atendamos a este escenario.

Con su propuesta de llevar la transculturación antropológica a la literatura (reconociendo, no obstante, sus diferencias), Rama intentaba registrar

${ }^{3}$ A juicio de Losada, en la "transculturación narrativa" propuesta por Rama existirían cuatro niveles de análisis no contradictorios, sino complementarios: "Uno general, el campo en que se trabaja, es decir entre Europa/Tradición. Otro subjetivo, cómo se internaliza esa oposición en la contradicción del espíritu productor, y de los textos producidos (son lo "mismo" Sarmiento, Borges, Aimé Césaire, y LO PRUEBA con una brillantez que es ejemplar). Y, finalmente, el proceso técnico de construcción de lenguajes, que se puede llamar formas de "apropiación" y, luego, "transformación". Por un lado, de cómo nos apropiamos y reformulamos la cultura europea (Borges, Lezama Lima). Por otro, la tradicional (J. M. Arguedas). Hay un cuarto sentido más limitado, que solo se refiere a esta última operación" (1985, pp. 268-269).

${ }^{4}$ Desde otra posición, Román de la Campa adjudica la persistencia de la categoría a sus resonancias ideológico-afectivas, en tanto "evoca un sentido impreciso pero generalizado de autoctonía y autenticidad latinoamericana” (1994, p. 14). 
dos quiebres. Uno en el campo del pensamiento crítico y literario latinoamericano, en tanto que llevaba a aquella zona intermedia de contacto anteriormente señalada las representaciones de espacios culturales populares, "zonas internas", históricamente excluidas del lugar pensable entre Europa y la sociedad tradicional latinoamericana, y que impositivamente siempre funcionó como sinécdoque de la nación. Franja intermedia que aún seguía siendo el referente de las dinámicas culturales en otras metáforas-concepto próximas en el tiempo, tales como Sistema literario, Malandraje, Calibán y Fuera de lugar. El otro quiebre apunta al proyecto crítico personal del propio Rama. Con la energía creadora tras la categoría de transculturación, el ensayista uruguayo intentó superar su precaria concepción de lo "tradicional" con la que operó en sus trabajos anteriores. Aquella forma de concebir la "tradición", que se aprecia en gran parte de sus textos de la década del sesenta, consistía en una definición por negaciones; tradición es todo aquello que se opone a lo moderno, como lo expone Alejandro Losada en un trabajo inconcluso dedicado a evaluar la interpretación pensada por Rama para articular los procesos sociales latinoamericanos a la "nueva narrativa” (Losada, 1985) que habría surgido durante la década de los sesenta.

Para lograr este doble quiebre, Rama piensa que las "zonas internas" de las naciones están compuestas por "valores idiosincráticos" que resisten a "la agresividad de las fuerzas modernizadoras". Por tanto, el proceso global que designa transculturación narrativa es el contacto agresivo de dos "estructuras autónomas", las que al momento de producirse su encuentro, terminan ambas sufriendo transformaciones a partir de pérdidas irremediables, selecciones, rescates y reconfiguraciones. Sin embargo, aquí surge un primer y considerable problema. Como expone Román de la Campa, "lo autónomo o lo autóctono no podrá ser un espacio estable de identidades y esencias si participa, incesantemente, en un proceso de intertextualidades amplias a través del mercado global de formas culturales" (1994, p. 16). Es decir, más allá de las dinámicas culturales ancladas en los textos narrativos que Rama examina, aún subyace un residual esencialismo regionalista que no acaba por disiparse del todo.

Este esencialismo residual en tanto constituyó largamente la figura de lo pensable del nacionalismo identitario latinoamericano, no solo se manifiesta a este nivel, también produce una reducción anterior y mucho más 
radical. En la interioridad de las culturas tradicionales aledañas al predominio urbano letrado, Rama articula una serie de diferencias que terminan por homogeneizarse, en cuanto pierden su propia historicidad, sus propios ritmos y tiempos históricos, con lo que, en definitiva, naturaliza a comunidades diferidas y diferenciales. Al interior de la estructura autónoma y autóctona pensada por Rama confluyen sincréticamente procesos históricos indígenas, regionales, afrodescendientes, entre otras importantes comunidades históricamente desplazadas. La articulación sincrética propuesta por el crítico uruguayo reconoce pérdidas, selecciones, recuperaciones y transformaciones, pero en tanto su producto final es una síntesis, no deja de estar asociada subrepticiamente al mestizaje. Es por este motivo que Antonio Cornejo Polar, una década después se referirá a transculturación narrativa como un concepto "harto más sofisticado que el de mestizaje", aunque mestizaje al fin y al cabo. El fondo negativo de esta reducción es que no otorga, finalmente, una herramienta crítica que cuestione, en su base, a la jerarquía de valores simbólicos del discurso universalizante de occidente o, a decir de Rolph-Michel Trouillot (2011), el discurso de los universales noratlánticos.

Esta convergencia hacia un producto sincrético final revela otros elementos residuales que se convierten en aporías de la propuesta. A este segundo elemento residual podemos denominarlo teleología modernizante. $Y$ es que en tanto la transculturación pretende lograr un sincretismo conflictivo, aunque sincretismo a fin de cuentas, siempre guarda un profundo sentido de producto final para ser alcanzado, en lugar de algo que simplemente ocurre o es. En este implícito deseo de futuro se pueden apreciar tanto las huellas de la "teoría de la dependencia" como del pensamiento identitario de la tradición autonomista latinoamericana, puesto que a lo que apunta en definitiva la transculturación es que las culturas regionales, en su lucha por no desaparecer, deben sincretizarse con la modernización. Es decir, se trata de un proceso que abarca pérdidas, ganancias, negociaciones, pero aún sometido a una lógica modernizante. O, en palabras de Alberto Moreiras, la transculturación solo es exitosa si "la cultura dominada es capaz de registrarse o inscribirse en la dominante”. Por ello, más allá de su avanzada propuesta metodológica, más allá de su lucha por romper el esencialismo nacionalista, transculturación narrativa no acaba por desapegarse de las demandas que eran el obstáculo epistemológico de 
la tradición crítica latinoamericana precedente. Es por esto que considero, sin desconocer sus notorias diferencias, a transculturación narrativa y no a Calibán como el último ensayo de la extensa e importante tradición identitaria latinoamericana ${ }^{5}$.

Estos dos aspectos problemáticos conducen, a su vez, a dos importantes efectos. Uno de alcances hermenéuticos y otro de alcance político. En primer lugar, una importante consideración hermenéutica. Como reconoce Alberto Moreiras, "la transculturación está, al fin y al cabo, en sí misma siempre de antemano transculturada". Esto debido a que el concepto "no nombra, a pesar de todo, un hecho primario o "natural", sino que es más bien una representación comprometida: como concepto hermenéutico, la transculturación resulta tan producida históricamente como los fenómenos a interpretar" (1997, p. 214). Esta sobreproducción histórica de transculturación narrativa recarga y por ello acaba contraponiéndose, tácita pero profundamente, a lo que el mismo Rama conceptualizó como "metodología derivada de los rasgos específicos latinoamericanos", uno de los grandes objetivos de la articulación entre literatura y sociedad durante el siglo veinte en el pensamiento crítico y literario latinoamericano ${ }^{6}$. Si entendemos a esta "metodología derivada de los rasgos específicos latinoamericanos" a partir de la idea de Gayatri Spivak de un "instrumento de estudio que participa de la naturaleza del objeto de estudio” (2013, pp. 329-330), podríamos

${ }^{5}$ A un respecto similar, Santiago expresará en su ensayo "A pesar de dependiente, universal": "Mientras más diferente sea el indio, menos civilizado es; y mientras menos civilizado sea, más niega al narciso europeo; mientras más niega al narciso europeo, más exigente y apremiante será la fuerza que lo transformará en una imagen semejante; mientras más se asemeje al europeo, menor será la fuerza de su propia alteridad" (2012, p. 100).

${ }^{6}$ Según lo expone Rama en su artículo "Literatura y sociedad", las demandas que con mayor fuerza recorren el pensamiento latinoamericano desde la década de 1920 en adelante son dos: por una parte, la idea de una "metodología derivada de sus rasgos históricos específicos" (124) y por otra, la adopción de una "perspectiva culturalista" (126), a las que de manera gradual se les sumarán los aportes de las tendencias de carácter renovador en el ámbito de las literaturas latinoamericanas, las ciencias sociales desarrolladas en el continente, las diversas coyunturas políticas, entre otras, para terminar formando un estrecho vínculo entre la producción literaria latinoamericana y su particular estructura social. Este artículo apareció bajo diferentes títulos en diversas publicaciones. Aparece como "Introducción” a Los Gauchipolíticos rioplatenses (Buenos Aires, Calicanto, 1976), como "Literatura y clase social" en el número uno de la revista Escritura (1976) y en la recopilación Lectura crítica de la literatura americana (Caracas, Ayacucho, 1996) y como "Literatura y sociedad" en la antología de Ángel Rama Literatura, cultura y sociedad en América Latina (2006). Las citas de este artículo siguen esta última versión. 
señalar que, en definitiva, el instrumento pensado y elaborado por Rama sobreexagera su propia naturaleza histórica.

En segundo lugar, al ontologizar importantes diferencias dentro de la estructura de las culturas regionales tradicionales, la propuesta de Rama conduce a un importante efecto político. En concreto, subsumir grupos sociales contrahegemónicos o de hegemonía alternativa trae como consecuencia algo que Neil Larsen ha expresado claramente: "La cultura en sí deviene el límite deshistorizador y naturalizador de lo que podría ser, contrariamente, la emergencia de una contra-racionalidad concreta directamente opuesta a la racionalidad del estado" (1990, p. 64). En otros términos, esta naturalización en la propuesta ramiana desenmascara y lleva hasta su límite -es decir, hasta su efecto político negativo- la idea de la cultura como capacidad liberadora propuesta por la modernidad, que llega a la crítica literaria latinoamericana desde la "perspectiva culturalista" adoptada paulatinamente desde la década de 1920. Por este motivo, como sostiene John Beverley, esta visión de la cultura no permitió abordar los diversos movimientos sociales contrahegemónicos y de hegemonía alternativa que subsistieron en América Latina a partir de los setenta y sobre todo en la década siguiente. Movimientos sociales que se mantuvieron resistiendo al interior de la coyuntura que entrecruza, por un lado, a los procesos dictatoriales padecidos por el continente con, por otro, el asentamiento del capitalismo transnacional que desestabilizaba a la idea tradicional de nación que la propuesta de Rama aún intenta preservar a partir de su opción sincrética.

La difuminación de una contra-racionalidad opuesta a la racionalidad del Estado, bajo la subyacente ideología del mestizaje manifestada en la teoría de Rama como fórmula conciliatoria y niveladora, genera también otro tipo de obliteraciones. No se trata tan solo de la reducción de procesos históricos particulares de diversas comunidades, sino que también termina por subsumir "lo cultural a lo letrado, lo letrado a lo urbano, lo latinoamericano a lo hegemónico" (1997, p. 142), como plantea Mabel Moraña. Toda esta cadena de reducciones tras la operación sincrética produjo que la recepción de la propuesta de Rama avanzara hacia la pregunta por la posición del intelectual en los procesos culturales. Tanto las fuerzas externas transnacionalizadoras que amenazaban la frontera de exclusión, como las fuerzas internas a la misma frontera -fuerzas internas que por lo demás representaban comunidades históricamente excluidas de los procesos ins- 
titucionales de los estados-nación- dejaban en evidencia que el intelectual ya no podía seguir asumiendo la posición de "representador, traductor e intérprete del sustrato de lo popular, categoría teórica -ideológica- situada a priori en el espacio utópico del interior de la nación, vale decir, en la interioridad de la teoría” (1997, p. 142).

En otras palabras, el rol mesiánico del crítico e intelectual, presente con fuerza desde el proceso emancipatorio americano y reforzado en el siglo XX por medio de la "utopía” de Pedro Henríquez Ureña llega, en transculturación narrativa, hasta su límite. En el sentido que señalan todas estas tensiones, Moraña expresa que

Quizá uno de los mayores desafíos de la conciencia latinoamericana de los setenta haya sido tratar de asimilar la imagen dislocada de un continente desagregado y ajeno de sí mismo, que se imagina sin embargo porfiadamente, a nivel nacional y continental, como comunidad posible, desde una posicionalidad carente de consenso, de territorio, situada "en ningún lugar” (1997, p. 138).

\section{Problemas socio-simbólicos en la interioridad de la teoría/ nación}

Como se aprecia, transculturación narrativa revela una serie de categorías fundamentales en la "elaboración" de la modernidad que, en su particular serie de paradojas, el debate en torno a otras metáforas culturales del periodo ya habían comenzado a señalar, tales como ideas fuera de lugar o Calibán; "Estado-nación”, "sociedad”, "literatura” y también el modo en que estos conceptos son articulados en la "interioridad de la teoría”. Dichas propuestas, junto a otras como Malandraje de Antonio Candido, o la misma Transculturación narrativa de Rama intentaban pensar los modos de agenciamiento del espacio letrado tradicional latinoamericano, pero a sus respectivas propuestas aún subyacían elementos consustanciales a la ontología del universalismo abstracto moderno, sobre todo aspectos esencialistas y teleológicos, que en tanto significantes flotantes generaron agudos problemas en sus teorizaciones y, por ende, profundas discrepancias en su recepción. Sintetizando sus problemas a nivel tanto social como simbólico, podemos explicar el asunto de la siguiente manera. 
Socialmente, el núcleo problemático referido, aún continente de resabios esencialistas y utopistas, puede explicarse a partir de la distinción entre diversidad cultural y diferencia cultural entregada por Homi Bhabha:

La diversidad cultural es un objeto epistemológico (la cultura como objeto del conocimiento empírico): mientras que la diferencia cultural es el proceso de la enunciación de la cultura como "cognoscible", autoritativa [authoritative], adecuada a la construcción de sistemas de identificación cultural. Si la diversidad cultural es una categoría de la ética, la estética o la etnología comparadas, la diferencia cultural es un proceso de significación mediante el cual las afirmaciones de la cultura y sobre la cultura diferencian, discriminan y autorizan la producción de campos de fuerza, referencia, aplicabilidad y capacidad. La diversidad cultural es el reconocimiento de contenidos y usos ya dados; contenida en un marco temporal de relativismo, da origen a ideas liberales de multiculturalismo, intercambio cultural o de la cultura de la humanidad. La diversidad cultural es también la representación de una retórica radical de la separación de culturas totalizadas que viven inmaculadas por la intertextualidad de sus ubicaciones históricas, a salvo en el utopismo de una memoria mítica de una identidad colectiva única. La diversidad cultural puede emerger aun como un sistema de la articulación y el intercambio de signos culturales en ciertos relatos antropológicos del primer estructuralismo (2002, pp. 54-55).

En otros términos, el multiculturalismo o diversidad cultural en tanto utopismo de una identidad colectiva única representa, en la época del capital transnacional o modernidad tardía, una operación eurocéntrica, debido a que, como expone Slavoj Žižek, al igual "que el capitalismo global supone la paradoja de la colonización sin Estado-Nación colonizador, el multiculturalismo promueve la eurocéntrica distancia y/o respeto hacia las culturas locales no-europeas" (2010, p. 64). Es por esto que el multiculturalismo constituye en definitiva "una forma inconfesada, invertida, autorreferencial de racismo, un «racismo que mantiene las distancias»: «respeta» la identidad del Otro, lo concibe como una comunidad «auténtica» y cerrada en sí misma respecto de la cual él, el multiculturalista, mantiene una distancia asentada sobre el privilegio de su posición universal" (2010, p. 64).

Es por las consecuencias de este mantenimiento de una posición universal privilegiada que también resulta deficitaria otra propuesta de la época de relacionar lo nacional a lo universal. Me refiero al "nacionalismo 
diferencial" de Haroldo de Campos, propuesto en su ensayo "De la razón antropofágica. Diálogo y diferencia en la cultura brasileña" . A pesar de que el objetivo de De Campos en este trabajo es combatir la "xenofobia monológica" para "pensar lo nacional en relación dialógica y dialéctica con lo universal", y a pesar también de que se aleja de la "teoría de la dependencia" al definir a la noción de subdesarrollo como "una excrecencia de la idea de progreso económico y social", el "nacionalismo diferencial" de De Campos sin dudas que supera al "nacionalismo ontológico" que tanto fustiga, pero sigue manteniendo como referente de la interacción universal/ tradicional a la nación en su concepción moderna. En efecto, el definir al "nacionalismo diferencial" como "el des-carácter, al contrario del carácter; la ruptura, en lugar del trazo lineal; la historiografía como gráfica sísmica de la fragmentación eversiva antes que como homologación tautológica de lo homogéneo" (1982, p. 13) doblega la parousía del trazo rectilíneo con el que fue pensado previamente la historia literaria latinoamericana, no obstante en su proposición de las rupturas el referente, aunque ampliado en su canon, sigue siendo el espacio nacional que reduce "lo cultural a lo letrado, lo letrado a lo urbano, lo latinoamericano a lo hegemónico". Por lo que su intento de propuesta "dialógica y diferencial" sigue manteniendo una privilegiada posición que lo acerca, irremisiblemente, a la diversidad cultural o multiculturalismo.

Si socialmente podemos evaluar las metáforas de transformación hasta acá señaladas en torno a la distinción "diferencia cultural/diversidad cultural", discursivamente las podemos juzgar en base a la diferenciación "producción textual/productividad textual". En occidente, el pivote de esta discusión lo constituye la recepción de Mijail Bajtín efectuada por Julia Kristeva, y su propuesta de interpretar el dialogismo y la polifonía bajtiniana como intertextualidad. Una de las, a mi juicio, mejores intérpretes de las ideas de Mijail Bajtín, la crítica francesa de ascendencia polaca M.-

${ }^{7} \mathrm{El}$ texto original data de 1980. Apareció publicado por primera vez en la revista Coloquio/Letras $\mathrm{N}^{\circ} 62$ (julio de 1981, Lisboa). Traducido al español aparece por vez primera en Vuelta $\mathrm{N}^{\circ} 68$ (junio de 1982, Ciudad de México). Las citas corresponden a esta última versión. El texto posteriormente conocería otras traducciones al español, asimismo como al inglés, italiano, francés y alemán. Sería incluido en 1992 en la recopilación de ensayos de Haroldo de Campos Metalinguagem e outras metas. 
Pierrette Malcuzynski, expresa contundentemente la discrepancia entre la proposición original del pensador ruso y la célebre conceptualización de Kristeva del siguiente modo:

C'est au niveau de cette multiplicité (polyphonique) de plans et de voix que semble intervenir l'intertextualité. Chez Bakhtine, où la notion d'intertextualité n'apparait jamais, la polyphonie vient marquer la particularité d'une PRODUCTION de la narrativité romanesque, c'est-à-dire l'interaction SOCIO esthétique de la production littéraire dans des conditions sociales, économiques et historiques spécifiques. Chez Kristeva, par contre, le polyphonique vient désigner la PRODUCTIVITÉ du texte, c'està- dire les divers mécanismes qui articulent les particularités du texte moderniste par rapport à celles du texte réaliste/symboliste (1984, p. 48$)^{8}$.

Por tanto, la franja que separa "producción" de "productividad" es el reconocimiento y aceptación de dos o más procesos de enunciación puestos en discurso, dos o más referentes que se entrecruzan sin llegar a obliterarse o, como en el caso de la propuesta de Rama, volverse sincréticos. Esta distinción entre "producción" y "productividad", relevante para el desarrollo de los estudios del discurso con orientación social, sirve como demarcador de los límites y consecuencias del estructuralismo -y en general de todas las propuestas de análisis inmanente- en su avance residual por diversas corrientes y propuestas que surgen a partir de la década del setenta. La idea de "productividad" señala las diversas transformaciones de los variados tipos discursivos (pérdidas, rescates, reconfiguraciones) tornando al proceso dialógico del intercambio social en un hecho sobreproducido históricamente, lo que acarrea la consecuencia de desvirtuar la naturaleza del objeto de

8 "Es a nivel de la multiplicidad (polifónica) de planos y voces que parece intervenir la intertextualidad. Para Bakhtine, en cuyos textos no aparece nunca la noción de intertextualidad, la polifonía viene a marcar la particularidad de una producción de la narratividad novelesca, es decir, la interacción socio-estética de la producción literaria en condiciones sociales, económicas e históricas especificas. En los textos de Kristeva, al contrario, la polifonía se refiere a la productividad del texto, es decir, los diferentes mecanismos que articulan las particularidades del texto modernista en comparación con las del texto realista / simbolista" (Traducción de Soléne Bergot Le Caer). 
estudio. La idea de "producción”, en tanto, pone énfasis en la interacción del discurso literario en sus particulares condiciones sociales, económicas e históricas específicas, reconociendo sus paradojas y contradicciones, lo que permite un reconocimiento del "otro" que lleva a cuestionar las jerarquías simbólicas impuestas por la ontología de los universales noratlánticos.

La distinción discursiva entre "producción" y "productividad" pone en tela de juicio la noción de Filtragem de Alfredo Bosi, otra de las metáforas de transformación ${ }^{9}$ de la época, en tanto que ella también se postula como una explicación del movimiento de las ideas en la modernidad. Desarrollada en su libro Dialetica da colonização (1992), la metáfora de filtragem encontró un polemista en Roberto Schwarz, quien sometió a escrutinio al concepto en su trabajo "Discutendo com Alfredo Bosi”. Allí Schwarz, no deja de reconocer que la propuesta de Bosi tiene méritos claros,

[C]omo o ganho em organicidade em relação a modelos mecânicos ou aleatórios da difusão do pensamento. Em especial as ligações muito assimétricas entre países ricos e pobres, adiantados e atrasados, centrais e periféricos, passam a ser olhadas com mais humanidade, e mais acerto, pois em lugar da imposição direta e unilateral somos levados a notar a eficácia, mesmo involuntária, da constituição interna da parte fraca, que nunca é totalmente passiva (1993, p. 21).

9 Para Hall, dentro del conjunto de metáforas por las cuales imaginamos el cambio cultural, las metáforas de transformación pueden ser definidas por dos aspectos. En primer lugar, nos deben permitir pensar qué ocurriría "se os valores culturais predominantes fossem questionados e transformados, se as velhas hierarquias sociais fossem derrubadas, se os velhos padrôes e normas desaparecessem ou fossem consumidos em um "festival de revoluçao", e novos significados e valores, novas configuraçôes socioculturais começassem a surgir" (2003, p. 219). Precisamente el aspecto que, por ejemplo, "Dialéctica del malandraje" de Antonio Candido deja entrever pero que no formaliza hasta sus últimas proposiciones. Y en segundo lugar, las metáforas de transformación deben poseer un valor analítico, en el sentido de entregar modos de hacer pensar las relaciones entre los dominios social y simbólico en el indisoluble proceso y lugar concreto que involucra la transformación. Lo que justamente es el fuerte del ensayo de Candido anteriormente referido. En este sentido, cuatro metáforas culturales postuladas en la década del setenta pueden ser consideradas como de transformación en el pensamiento crítico y literario latinoamericano. Estas son Entre lugar (1971) de Silviano Santiago, Fuera de lugar (1973) de Roberto Schwarz, Transculturación narrativa (1974) de Ángel Rama y Heterogeneidad cultural (1978) de Antonio Cornejo Polar. 
No obstante, la metáfora de igual modo plantea los problemas que precisamente hemos venido comentando

[A] metáfora do filtro tem também implicações menos realistas quanto à cena contemporânea. A sua inspiração profunda, que manda resgatar a iniciativa e produtividade dos oprimidos, tem como outra face um esquema simples, polarizado entre unidades e o que não são elas. Pensando um pouco, nos daremos conta de que os "contextos específicos" através dos quais a filtragem opera funcionam como instâncias finais. Em conseqüência multiplicam-se os âmbitos restritos de reprocessamento de idéias -se é possível dizer assim- exteriores uns aos outros e mal ou bem iguais em eficácia e direito. De tal sorte, vindo ao exemplo brasileiro, que a acepção européia do liberalismo não pesaria sobre a nossa, que só devido a engano passaria por ser inadequada. Ora, este arquipélago de âmbitos independentes difere muito do que a observação ensina sobre o espaço das idéias e da vida prática em nosso tempo, estruturado por condições e antagonismos globais, sem cuja presença as diferenças locais ou nacionais não se entendem, e aquém de cuja complexidade mesmo que apenas indicada- as questões ideológicas não se discutem razoavelmente. $\mathrm{O}$ mal-estar brasileiro em relação às idéias modernas, de que o sentimento de inadequação do liberalismo é uma instância, pertence a esta esfera dos efeitos globais, de incompatibilidade e copresença de pontos de vista engendrados no interior e em diferentes lugares de um sistema transnacional, que a noção de filtragem, com o seu viés localista, tende a desconhecer. Assim, longe de ser um traço inconseqüente, a discrepância entre a feição local das relações sociais e a sua norma contemporânea, mesmo remota, pertence estrutural e objetivamente à dialética global do sistema, à qual dá acesso, devendo ser estudada, e não descartada, ainda quando os mecanismos de filtragem a abafem ao máximo (1993, p. 21).

Por lo que, el énfasis en la "productividad" local del filtro tiende a desconocer la "producción" de los antagonismos globales, esto a su vez trae aparejado como consecuencia el hecho de que las diferencias locales no pueden ser asumidas y problematizadas con propiedad. Precisamente el punto que Schwarz nunca recapituló de su proposición, y el cual optó por defender a ultranza. A mi juicio, las dos propuestas que más amplifican las posibilidades del límite apuntado en los últimos párrafos, son heterogeneidad cultural de Antonio Cornejo Polar y Entre-lugar de Silviano Santiago. 


\section{Desgarramientos críticos en la centralidad de la letra y los letrados}

Una parte de los trabajos críticos sobre transculturación narrativa que se han propuesto explorar los excedentes o "desgarramientos" del proceso sincrético han apuntado precisamente a leer la contraparte de la "gesta del transculturador". Me refiero a ensayos como los de Silvia Spitta o Alberto Moreiras $^{10}$, éste último retomando el texto póstumo de Arguedas, uno de los transculturadores a los que Rama prestó mayor atención. En El zorro de arriba y el zorro de abajo Moreiras atisba las contradicciones inherentes a la operación transculturadora, y por ende a algunas de las lógicas más relevantes del pensamiento occidental:

El logro epocal de Arguedas contra toda transculturación, es decir, la producción de un texto literario en el que puede decirse que una racionalidad contrahegemónica da razón, o da el principio mismo de razón, de la modernidad, tal logro, en el que quizá no puede pensarse lo bastante, por razones esenciales, no podrá ser leído más allá o aparte del suicidio textual, literal, de Arguedas. En el momento en que la tensión interna de Arguedas le hace posible avanzar, negativamente, hacia una resolución de la problemática textual, la contradicción entre racionalidades que forma la base del fenómeno transculturador se invierte, y a partir de esa inversión, aunque no en ella, se produce la catástrofe. El resultado catastrófico no es, por cierto, que un momento puntual de no contradicción o de verdad metahermenéutica surja, sino que una fisura aporética se abre en el sentido, y que la disfunción ofrece, para Arguedas, pérdida incalculable y parálisis de producción (1997, p. 225).

En el caso de Spitta, su argumentación permite interpretar alguno de los últimos textos de Rama que, de alguna u otra forma, reconocerían implícitamente las limitaciones de la labor crítica como filtragem o articulación subsume diferencias irreconciliables. El ensayo al que se refiere Spitta en su texto es "El escritor latinoamericano como traidor (Más allá de Yo el

${ }^{10}$ Spitta (1997) y Moreiras (1997). Ambos aparecen compilados en Ángel Rama y los estudios literarios latinoamericanos (Moraña, 1997). 
supremo)" "11, trabajo enfocado en el relato de Augusto Roa Bastos "El sonámbulo", recién publicado por vez primera en 1988. En su ensayo Spitta rescata el violento desgarramiento con que Rama imagina los procesos de transculturación, pero que aparecen mitigados irremediablemente en su opción sincrética final. Esta imagen del crítico y su operación intelectual es confrontada por Rama en su análisis del cuento de Roa Bastos, analizando e interpretando la figura del intelectual (el escribano Silvestre Carmona en el relato) como un traidor. "El intelectual es fatalmente un traidor, a partir de su ejercicio de la escritura y, con ella, del sistema racionalizado, individualizado y egoísta, que llevó adelante el mundo europeo al promover la revolución burguesa. No hay otra solución para él. Siempre será traidor y todo ejercicio de la escritura será una traición más" (1988, p. 206), concluye Rama en su artículo. Este trabajo publicado póstumamente puede relacionarse a otro texto del archivo ramiano, el cual resulta interesante por razones de re-escritura. Me refiero a "Rodolfo Walsh: la narrativa en el conflicto de las culturas" (1983). En este ensayo pueden apreciarse los vertiginosos cambios políticos experimentados en América Latina durante la segunda mitad de los setenta y primera de los ochenta (los últimos años de la vida de Rama) y como ello se arraiga no solo en la mundaneidad (Said, 2004) del texto, también en los modos de transformación por parte del crítico al articular lo social y lo simbólico. Precisamente la nota al pie de la versión publicada el año 1983 (año de la muerte de Rama) del trabajo aludido dice lo siguiente:

Este ensayo fue escrito en 1974, atendiendo a las entonces recientes circunstancias políticas argentinas: retiro del militarismo después de siete años de ejercicio del poder, elecciones que consagraron a Héctor Cámpora y la legal traslación a éste de la presidencia por parte del general Lanusse, posterior renuncia de Cámpora y elección de Juan Domingo Perón con el 61,8 por ciento de los votantes, triunfo del peronismo a pesar de sus primeras escisiones internas, visibles desde los sucesos de

${ }^{11}$ En Nuevo texto crítico I/2 (segundo semestre, 1988). Por su parte, el relato de Roa Bastos apareció publicado en el volumen editado por Marta Dujovne (1984), Cándido López y un texto de Augusto Roa Bastos. Milano: Franco María Ricci. 
Ezeiza a la llegada del dirigente exiliado. Los sucesos posteriores -muerte de Perón y ascensión a la presidencia de su esposa Isabel Martínez, conducción derechista a cargo de López Rega, ruptura del frente peronista, crisis económica, acción de la guerrilla montonera y la del ERP, golpe de Estado del ejército en marzo de 1976 con el ascenso del general Videla a la presidencia, represión de la insurgencia y del gremialismo, política económica fondomonetarista- son incidentes del mismo proceso en uno de sus periodos regresivos, sólo diferentes en grado respecto de otros similares momentos de regresión, en que también el ejército entró a contener los intentos de modificación de la estructura económica y social del país (1983, pp. 261-262).

Escrito en 1974, publicado en 1976, re-escrito y vuelto a publicar en 1983, las transformaciones del ensayo se articulan a las transformaciones sufridas por las condiciones de lectura que exige la obra del escritor en cuestión. El ensayo sigue un camino temporal casi exactamente paralelo al recorrido por Transculturación narrativa desde su publicación en artículo (1974) a su versión ampliada y desarrollada en libro (1982), sin embargo constituye su reverso. Las tensiones políticas y sociales y su relación al interior de la cultura son analizadas en la medida del desgarro, del conflicto irremediable que significan como ruptura de todo utopismo modernizante posible, develados a partir de los discursos y prácticas de Rodolfo Walsh.

Aun otro reverso de las aporías de Transculturación narrativa puede leerse en La ciudad letrada (2004 [1984]). Póstumo e inconcluso, con todos los aspectos deficitarios que ello conlleva y que de hecho han sido recalcados por la crítica en su evaluación, es sin lugar a dudas un giro radical en el proyecto crítico de Rama, sobre todo en la perspectiva con la que él interpretó la encrucijada modernidad-literatura. La ciudad letrada significa una fuerte crítica, y autocrítica también, a la "ideología de lo literario" según Beverley, o a la "versión cultista de cultura" de acuerdo a Brunner. Y no tan sólo giro radical en el proyecto crítico del propio Rama, sino también gozne entre el proyecto crítico latinoamericano surgido a partir de los sesenta y el proyecto que iba a comenzar a asentarse desde la década de los ochenta. El primero influido socialmente por la Revolución cubana y discursivamente por la "nueva narrativa hispanoamericana", el segundo, a su vez, empujado socialmente por la Revolución nicaragüense y discursiva- 
mente por el auge del testimonio y el archivo colonial hispanoamericano. John Beverley lo expresa, a modo de confesión, en su ensayo "La política de la teoría: un itinerario personal":

Lo que Rama nos hizo ver, o lo que queríamos ver en su libro, fue que la literatura en sí -incluso las "novelas del boom" o la "poesía conversacional” promulgada por los cubanos- estaba implicada en la formación de las elites tanto coloniales como post-coloniales en un lugar donde las voces populares podrían encontrar mayor y mejor expresión, un vehículo para la democratización cultural, quedó cuestionada en sus mismas bases. El argumento de Rama explicaba, por un lado, cómo la literatura llegó a tener el tipo de centralidad que todavía tiene en América Latina (escribo estas palabras en vísperas de la celebración del cumpleaños de Gabriel García Márquez en Colombia). Pero, por otro lado, perfiló también ese sentido de los límites de la literatura como representación (en el doble sentido de hablar por -político- y hablar de -mimético) adecuada del sujeto social latinoamericano (2011, pp. 81-82).

La literatura como práctica constituyente de las elites, o en otros términos, como práctica de preservación del "colonialismo interno" (Silvia Rivera Cusicanqui) llega hasta su límite en la discusión que se arrastra desde Transculturación narrativa hacia La ciudad letrada. Límite representado en la distinción "hablar por/hablar de" subsumida en una operación cultural sincrética desde la metáfora del mestizaje hasta transculturación. En efecto, las metáforas culturales comentadas y analizadas hasta acá tenían como uno de sus objetivos romper con la naturalización del sentido y el significado construidos desde la ontología de los universales abstractos, sin embargo, en su intento, culminaban operando una segunda reducción. Esta segunda reducción preservaba el verticalismo tradicional de la relación centro-periferia al tratar de pensar el interior de las naciones, lo que arrastraba hacia otro nivel el fenómeno de homogeneización, constituyéndose esta estrategia en definitiva, como un registro de "colonialismo interno". En este sentido, cabe destacar que la "metáfora de transformación" heterogeneidad cultural postulada por Antonio Cornejo Polar intentaba justamente problematizar este modo de pensar lo nacional, teniendo para ello como precedente el rescate residual del pensamiento de José Carlos Mariátegui. En los primeros artículos en los que formalizaba su categoría, Cornejo Polar advertía este movimiento reductor y homogeneizador propio 
de la imaginación crítica latinoamericana descrito en el párrafo anterior. De hecho, es su evidencia para deslindar las "literaturas homogéneas" de las "heterogéneas"12.

\section{Apunte final. Transculturación narrativa: historia de una violencia sobredeterminada}

Atisbar ciertos momentos de la travesía histórica de transculturación narrativa nos permite una reflexión sobre lo que podríamos pensar, a partir de Volóshinov, como la "multiacentualidad" de los conceptos. Es decir, aquellas densas capas de significación que van quedando aprehendidas, asidas a las propuestas conceptuales, en el transcurso de sus errancias por diversas disciplinas, diferentes proyectos ideológicos y distintos espacios geopolíticos. Errancia que podríamos denominar como travesía material significante, entendiendo por material a efectos contextuales en lugar de aspectos formales. Si asumimos con Cornejo Polar que tras las "metáforas culturales" contra las que él despotrica en su último texto se encuentra una irremediable distancia entre "capacidad hermenéutica" y "rendimiento teórico" es porque, precisamente, el fundamento organizativo de aquella relación se encontraba desbaratado. Se había levantado una separación irreductible entre experiencia y teoría. $\mathrm{O}$, para decirlo de modo más específico, la distancia entre "capacidad hermenéutica" y "rendimiento teórico" indica una discrepancia entre "circulación del sentido" y "construcción del significado". El hecho de que Cornejo asuma que las categorías ya no pueden dar cuenta de la totalidad de la problemática en la que se insertan podemos comprenderlo como un espacio de profundo escepticismo entre el significado y el sentido. De esta distancia surge una triple violencia -social, simbólica, epistémica- si discursivamente entendemos por tal a una

${ }^{12}$ Por ejemplo, en el artículo de 1978 "El indigenismo y las literaturas heterogéneas: su doble estatuto socio-cultural", se constata que la "producción literaria circula, entonces, dentro de un solo espacio social y cobra un grado muy alto de homogeneidad: es, podría decirse, una sociedad que se habla a sí misma" (Cornejo Polar, 1978, p. 11). Siendo precisamente esta superposición enunciativa de "hablar por/hablar de" lo que produce la "movilización de todas las instancias del proceso literario dentro de un mismo orden sociocultural" determinando así "el surgimiento de las literaturas homogéneas" (1978, p. 11). 
separación desgarrada, y en algunos casos irremisible, entre significado y sentido. La travesía material significante de Transculturación narrativa constituye, a fin de cuentas, un nodo conceptual al cual quedan aprehendidas, de manera sobredeterminada, una serie de violencias que recorren un momento crucial de la historia latinoamericana durante el siglo XX.

\section{Referencias}

Beverley, J. (2011). Políticas de la teoría. Caracas: CELARG.

Bhabha, H. (2002). El lugar de la cultura. Buenos Aires: Ediciones Manantial. Bosi, A. (1992). Dialética da Colonização. São Paulo: Companhia das Letras. . (2005). Cultura brasileña: una dialéctica de la colonización. Salamanca: Universidad de Salamanca.

Candido, A. (1991 [1970]). Crítica Radical. Caracas: Biblioteca Ayacucho.

Cornejo Polar, A. (1978). El indigenismo y las literaturas heterogéneas: Su doble estatuto socio-cultural. Revista de Crítica Literaria Latinoamericana, 7/8, 7-21.

De Campos, H. (1982). De la razón antropofágica. Diálogo y diferencia en la cultura brasileña. Vuelta, 68, 12-19. . (1992). Metalinguagem e outras metas: ensaios de teoria e crítica literária. São Paulo: Perspectivas.

De la Campa, R. (1994). Hibridez posmoderna y transculturación: Políticas de montaje en torno a Latinoamérica. Hispamérica, 69, 3-22.

Hall, S. (2003). Da Diáspora. Belo Horizonte: UFMG.

Laclau, E. (1995). Emancipación y diferencia. Buenos Aires: Ariel.

Laclau, E. y Mouffe, C. (1987). Hegemonía y estrategia socialista. Madrid: Siglo XXI.

Larsen, N. (1990). Modernism and Hegemony. Minneapolis: University of Minnesota Press.

Losada, A. (1985). "Nueva Novela" y procesos sociales en América Latina. Texto Crítico, 31/32, 246-270.

Malcuzynski, M.-P. (1984). Critique de la (dé)raison polyphonique. Études Françaises, 20, 45-56.

Moraña, M. (1997). Ideología de la transculturación. En M. Moraña (ed.), Ángel Rama y los estudios literarios latinoamericanos (pp. 137-145). Pittsburgh: IILI.

Moreiras, A. (1997). José María Arguedas y el fin de la transculturación. En M. Moraña (ed.), Ángel Rama y los estudios literarios latinoamericanos (pp. 213-233). Pittsburgh: IILI. 
Ortiz, F. (1987 [1940]). Contrapunteo cubano del tabaco y el azúcar. Caracas: Fundación Biblioteca Ayacucho.

Rama, Á. (1983). Rodolfo Walsh: la narrativa en el conflicto de las culturas. Literatura y clase social (pp. 195-230). México: Folio. . (1988). El escritor latinoamericano como traidor (Más allá de Yo el supremo). Nuevo Texto Crítico, 2, 199-208. . (2004 [1984]). La ciudad letrada. Santiago: Tajamar. . (2006). Literatura, cultura, sociedad en América Latina. Montevideo: Trilce. . (2007). Transculturación narrativa en América Latina. Buenos Aires: El Andariego.

Said, E. (2004). El mundo, el texto y el crítico. Buenos Aires: Debate.

Santiago, S. (2012). Una literatura en los trópicos. Concepción: Escaparate.

Schwarz, R. (1993). Discutindo com Alfredo Bosi. Novos Estudos, 36, 9-22.

Spitta, S. (1997). Traición y transculturación: los desgarramientos del pensamiento latinoamericano. En M. Moraña (ed.), Ángel Rama y los estudios literarios latinoamericanos (pp. 173-191). Pittsburgh: IILI.

Spivak, G. (2013). En otras palabras, en otros mundos. Buenos Aires: Paidós. Trouillot, R-M. (2011). Moderno de otro modo. Lecciones caribeñas desde el lugar del salvaje. Tabula Rasa, 14, 79-97.

Žižek, S. (2010). En defensa de la intolerancia. Barcelona: Diario público. 